\title{
Air quality management: a mining perspective
}

\author{
F. Schwegler \\ Anglo Technical Division, South Africa
}

\begin{abstract}
Air quality management issues relating to mining are mainly centred around particulate impacts. These include dust deposition, and health impacts associated with PM10 and PM2.5 and the mineralogy and chemical composition of the particles.
\end{abstract}

Generally dust deposition is the focus of mine air quality management, but this is increasingly shifting toward management of the other aspects of particulate emissions as detailed above.

Historically air quality management on mines has been hindered by the complexity of all the potential emission sources. This is mainly due to the wide range of source types, the fact that most are diffuse and highly variable in nature, difficult to measure, and site-specific in terms of silt and moisture contents. Environmental factors such as temperature, rainfall and humidity compound emissions uncertainties. Mines are not static, and have continuously changing footprints with respect to haul road location and distance, the size of waste rock and tailings sites, and have varying production and mine development rates.

Much progress has been made in estimating emissions, and flexible, user-friendly source inventory management packages are now available to enable the continuous on-site maintenance of source inventories.

Dispersion modelling is an integral component of mine air quality planning, and particularly in the mine planning phase where detailed models can be used to inform on the location of certain activities, and the controls required to adequately manage air emissions.

A systematic risk-based air quality management planning is proposed to ensure that air quality management is properly integrated into the mining operation, is compatible with community and regulatory expectations, incorporates future mine development changes, and is continuously reassessed and improved to ensure air quality management is optimally managed throughout the life of the mine.

Keywords: mining, minerals, ore, air, quality, management, tailings, waste rock, particulate, PM10, PM2.5, dispersion, modelling. 


\section{Introduction}

Air quality management issues in mining and ore beneficiation are primarily centred on particulate emissions. Minerals processing through metallurgical processes often results in the emission of $\mathrm{NO}_{\mathrm{x}}$ and $\mathrm{SO}_{\mathrm{x}}$ as well as certain metals and fumes which are sometimes as important if not more important than the particulate emissions from these processes.

We can differentiate between some of the controls used for emission management from mining and from minerals processing. In mining, much focus is placed on prevention of pollution, since the sources tend to be more diffuse, whereas in minerals processing the technologies are focussed toward capture and treatment of emissions. This paper will focus on the management of dust emissions from mining and associated waste disposal facilities.

Sources of dust on mines result mainly from blasting, handling, processing or transporting of materials, or can be suspended from disturbed areas or waste disposal facilities, including waste rock and tailings, by wind erosion $[2,3]$. These need to be addressed in comprehensive Environmental Management Plans. These plans frequently do not go far enough toward management of dust emissions because they do not properly integrate air quality management into mine environmental planning, and are not based on a good solid understanding of the possible air quality impacts. The reasons for this are explained further in this paper, but can be attributed mainly to the complexities in estimating emissions from mines and the activities on mines.

Mines require the consolidation of air quality management into a single, integrated air quality management plan which addresses all sources, relative impacts, abatement measures, procedures, responsibilities, monitoring and performance assessment methods. This should ensure that, at any time and under any usual set of conditions, and at any stage in the mine's lifecycle from mine planning, operation to closure air quality is managed to within acceptable levels. Although not quantifiable, such an approach can result in fewer downthe-line costs and facilitate the mine's effective "licence to operate", as it is often referred to in Sustainable Development terms, which includes access to minerals as well as financial support.

Community and regulator engagement in this process is critical. Air Quality management in Europe is largely regulator-driven, however, mining operations, many of which are in developing countries or in remote areas, do not have this same level of regulatory competence and involvement. It is therefore often up to the mines to manage themselves with respect to air quality impacts. The UK LAQM model is very useful for this and many of the principles can be adapted to a mine-specific context. Of course, difficulties often arise from uncertainties relating to the extent of emissions from other nearby sources - this is information which is accessible to a regulator, but not always to individual industries and mines in an area, and this lack of information means that some assumptions regarding external influences to air quality need to be made. 


\section{Mine dust impacts}

Mines can be classified as either underground mines or open pit mines. In some cases a combination of open pit and underground mining occurs, although usually sequentially in the mine life-cycle, rather than simultaneously. At underground mines the rock dumps, tailings dams, and load-out facilities are the main causes of dust emissions, whereas at open pit mines the same sources exist, with additional sources including blasting, loading, haulage, clearing, and from a greater extent of surface disturbance and exposure.

Mine tailings are made up of fine particles. When dry these particles can be a source of serious dust problems. For example, in Gauteng, South Africa, disused tailings storage facilities generate dust on windy days that can impact over a wide area, particularly during dry months. In some cases this can be so bad that residents living close to these old impoundments take refuge in their homes.

Mine dust is often, incorrectly, considered to be chemically inert. However, the amount of fine dust, PM10 and 2.5, and the chemical and mineralogical composition of the dust generated by a mine will often ultimately dictate the potential for health impacts.

The control of "nuisance" dust which is deposited in the vicinity of a mine is often the primary focus of air quality management at the expense of managing the fine particles with their associated health effects. Dust-deposition monitoring networks are typically well developed on most mines. Although there is usually a correlation between deposited dust and fine suspended dust emissions from a single source, this is not always the case in mining where, due to the complexity and variability of mining operations these correlations cannot be used to reliably indicate PM10 or PM2.5 emission rates and environmental concentrations. Essentially, the control of dust deposition on its own is not sufficient, on its own, for air quality management control.

Dust types which are a particular nuisance originate from coal and iron ore mining. These cause discolouration, and in some cases permanent damage. In the case of iron ore, these types of impacts occur near the operations, shipping zones, and particularly in the vicinity of material handling or transfer points associated with these.

\section{Mine dust control}

Dust control has to be built into every aspect of the mines planning and operation. Of critical importance is the workforce, who need to be made aware of the importance of dust control, the methods which are used, procedures concerned, and the impact on non-adherence to these. The activities which require planned controls include construction, topsoil stripping, blasting, road transport, material handling and transfer systems, and rehabilitation programmes. Work practices then need to be planned so that control measures are integrated.

The main areas which require long-term control include:

○ Roads

○ Processing of minerals, including crushing and screening 


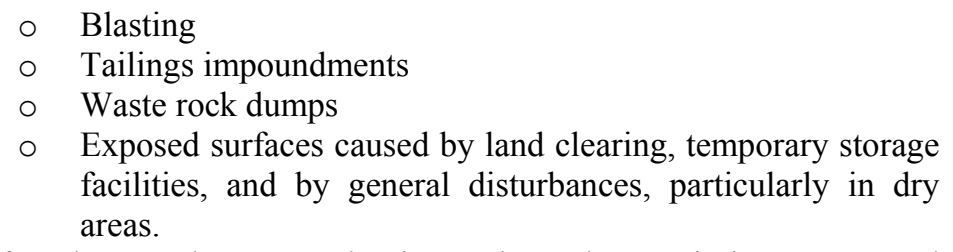

We have found examples on coal mines where dust emissions generated through wind erosion are an order of magnitude higher than those emitted from mine vehicles on unpaved roads. This reinforces the value of having sound rehabilitation programmes which keep up with the mine plan.

Surface wetting is not a sustainable long-term solution to dust emissions from waste rock dumps, tailings impoundments, or other exposed surfaces and can definitely not continue indefinitely post-closure. A permanent method of rehabilitation needs to be established. In some climates this can take the form of a vegetative cover, while in more arid regions it may be necessary to apply coarse cladding to the surface $[2,4]$.

Control cannot be effective without understanding the nature, distribution and intensity of each source. This requires continual source inventory maintenance, dispersion modelling and ambient air quality monitoring as a feedback mechanism.

It has been proposed that by mixing or co-disposing of some mine wastes, such as tailings and waste rock then facilities which are both physically and chemically more stable could result [4]. One of the main advantages of this is that the fine particles from tailings will occupy the voids between the coarser waste rock, thereby excluding oxygen from air and reducing potential acid drainage, as well as reducing suspension of dust through wind erosion. Codisposal is currently mainly used in the coal mining sector, particularly in Australia.

The importance of mine planning should not be underestimated. Retrospective control of dust issues is costly or impractical. For example, the location of mineral processing facilities, haul roads, waste or rock dumps are easy to plan and locate early in a project, but often near impossible to move after the operation has commenced. If these happen to be located in the "wrong" place, such as too close to a community, or in terms of prevailing wind direction, this could result in dust impacts which are difficult or impossible to rectify.

Emission standards are typically applied only to point source industrial emissions, and not to fugitive sources such as open pit mining or tailings dams, other than to specify that all reasonable and practical measures need to be taken.

The modern era of air quality management, which is emanating largely out of Europe and being adapted by some countries internationally, is not solely concerned with point source emissions and emission standards for these but rather on the receiving environment. Regulators are increasingly being tasked to manage regional air quality, which means that all sources need to be considered and controls need to be applied where appropriate. In essence this means that mines will increasingly have to manage their impacts through dynamic and 
regularly maintained source inventories, dispersion modelling and air quality monitoring.

\section{Dispersion modelling in mining}

The complexity in the measurement and prediction of dust from mining sites, as well as the wide number of sources and source types, many of which are diffuse and can be highly variable, has meant that dust emission control planning tools have been limited in the past, relative to other sectors.

For example, climatic factors such as rainfall, temperature, wind characteristics have a direct impact on the amount of dust generated by a mine, which is in contrast to a point source such as a stack, where process conditions dictate emission rates which can also be accurately monitored.

Despite this, dust dispersion modelling methods have progressed to the point that mines are often expected to use models in the planning stage of mine development [5].

Validation studies of mine modelling studies which include comprehensive and properly constructed emissions inventories, appropriate models and meteorological data provide reasonably accurate annual average deposition rates. Logistical and capacity constraints and the high level of variability in operations and environmental conditions on mines are the main reasons for limiting dispersion modelling applications for short-term dust exposures. More work in this field is required [2].

Emission inventories for mines, particularly open-cast mines, are generally far more complex than those generated for industry. The typical emissions inventory for a mine will include:

- Haul roads: Geographical location and lengths of segments; number of vehicles, and vehicle types

- Exposed surfaces: Area and geographical location of these areas

- Blasting data: Size and frequency of blasting

- Material properties: Exposed surfaces and mined material moisture and silt content

- Controls: Emissions estimates need to be modified to account for dust emission controls such as watering, revegetation, and chemical dust suppressants.

The emissions inventory should distinguish between Total Suspended Particulates (TSP), PM10 and PM2.5. Standard emission factors should be applied with caution since inaccuracies in developing an important emission factor will carry the error through to the model.

The objective of dispersion model application should determine how it is undertaken and the level of effort and detail required in setting up the model parameters. For example, if the objective of such an exercise is for mineplanning purposes, fairly detailed work needs to be undertaken since monitoring cannot be undertaken and impacts are purely speculative, requiring potentially costly controls. If, however, the objective is to manage emissions from an 
existing mining operation, air dispersion modelling can predominantly be used to prioritise the management of sources which contribute most to air quality impacts which can be monitored. This need not be to the same level of accuracy as for mine planning purposes, and the effectiveness of controls can then be assessed through monitoring, and an iterative approach can be taken to optimise the controls, how they are applied and focused on the various types of sources [2]. Such empirical methods can be highly effective, but require workforce participation and an integration of air quality management into all mining activities.

This type of approach can also be applied to spontaneous combustion, where source inventory maintenance and accuracy is highly problematic. A controlmonitor-control cyclical approach is recommended for this.

\section{Air quality management planning}

Air quality management planning is an objectives-oriented exercise, and in mining is often highly situation and activity specific. As in any air quality management exercise, significant value is gained by setting down firm objectives before considering the air quality management options in much detail.

Often objectives are compliance-oriented. However, in practice many other factors influence the pressures to which mines are subjected, including agriculture, community perceptions, and the increasing application of international standards rather that country-specific standards which, in developing countries, are often less strict than developing countries.

The consideration of real impacts in the specific context of the mine, including aspects such as agriculture and community locations should inform an air quality management plan to at least the same degree as compliance requirements. Compliance requirements are not uncommonly inadequate to ensure sufficient protection to humans and the environment. The process as illustrated in Figure 1 is a useful generic risk-based approach to air quality management planning from mines. Considerations that need to be brought into the management plan, and the stage at which they need to become incorporated, are listed down the right-hand-side of Figure 1.

It is critical to involve communities and regulators when compiling an air quality management plan, and to obtain their approval of the plan.

Monitoring techniques are able to accurately measure ambient dust levels on a real-time basis, and relay this through to operators on the mine. This is effective as an early warning of potential exceedances and can, if properly set up, be used to modify mining activities such that emission levels are controlled to an acceptable level. Long-term monitoring of ambient air quality is also necessary to assess the effectiveness of the air quality management plan which needs to be adjusted accordingly to ensure optimal air quality management. 


\section{Conclusion}

Air quality management in mining is a complex task, mainly due to the wide range of source types, the fact that most are diffuse and highly variable in nature, difficult to measure, and site-specific in terms of silt and moisture contents. Environmental factors such as temperature, rainfall and humidity compound emissions uncertainties. Mines are not static, and have continuously changing footprints with respect to haul road location and distance, the size of waste rock and tailings sites, and have varying production and mine development rates.

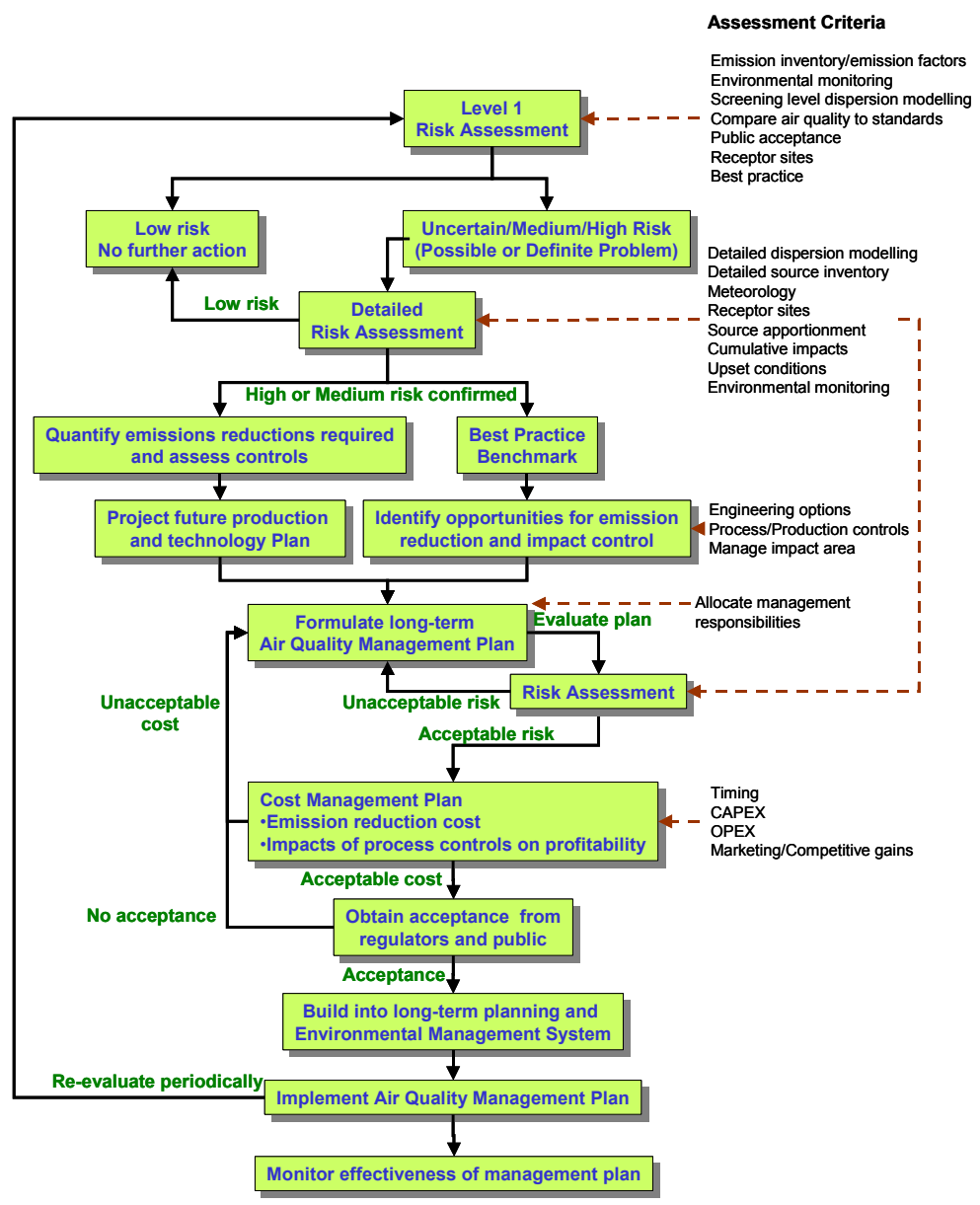

Figure 1: $\quad$ Air quality management planning - risk-based approach.

For this reason, it is imperative to use flexible, operator-friendly source inventories which can be maintained on a regular basis by mine operators. 
Dust deposition monitoring, which is usually adequately conducted at mines, does not go far enough toward integrated air quality management which needs to include, as a minimum, the management of PM10 and PM2.5, taking the chemical and mineralogical composition of the dust into consideration. Secondary particulate emissions arising from spontaneous combustion at coal mines are an example of where this would be of high importance.

Dispersion modelling can contribute significantly towards effective air quality management on mines, but is reliant on up-to-date flexible and user-friendly source inventory used as input data. This is useful at the planning, operational and closure phases of mining, but is optimally applied during the planning phase by reducing the risk of implementing a mine design which causes impacts which are far more costly to remedy once the mine has been commissioned.

The systematic application of controls is made possible through better understanding of various mine dust emission sources. These controls are effective only if the workforce has bought into the need for the controls, and if they are applied according to set procedures which can be modified at short notice to adjust for any changes.

The application of a risk-based systematic approach to developing an air quality management plan, and continual re-assessment of the plan helps to ensure that all sources are properly identified, prioritised, and optimum controls are implemented, would have a significant influence on the quality of an air quality management plan. Separating the various elements of air quality management into a single plan has also been shown to increase focus on air quality management, and to ensure that sources and activities are controlled according to set standards.

\section{References}

[1] Burger, L., Personal Communication, 25 January 2006, Director, Airshed Planning Professionals, Johannesburg, South Africa.

[2] Environment Australia, Best Practice Environmental Management in Mining, ISBN 064254570 7, 1998.

[3] Reed, W.R., An Improved Model for Prediction of PM 10 from Surface Mining Operations, Virginia Polytechnic Institute and State University, 2003.

[4] Mining, Minerals and Sustainable Development (MMSD) Project, Breaking new ground: the report of the Mining, Minerals, and Sustainable Development Project, May 2002. Published by Earthscan for IIED and WBCSD, 2002.

[5] Air Permitting Guidelines, Virginia Department of Environmental Quality Online. www.townhall.state.va.us. 